\title{
Contestação de
}

Normas e Ameaça à

Paz e à Segurança

Regional e

Internacional: A

Facilidade

Excessiva de

Acesso a Armas*

\section{Denise Garcia **}

[...] os líderes mundiais precisam aceitar o fato de que não podemos deixar [...] o livre mercado reger o comércio internacional de armas.

Oscar Arias, presidente da Costa Rica, Prêmio Nobel da Paz

A facilidade de acesso a armas por atores tanto governamentais quanto não governamentais exacerba conflitos, destrói acordos de paz frágeis e facilita a manutenção de violações aos direitos humanos e crimes egrégios contra a humanidade. Atualmente, não há nenhum tratado internacional abrangente e legalmente vinculativo que regule todos os aspectos da transferência de armas, deixando o comércio de arma-

\footnotetext{
* Artigo recebido em 22 de agosto de 2011 e aprovado para publicação em 29 de fevereiro de 2012. Traduzido por Paulo Chamon. E-mail: paulochamon@gmail.com. A autora é grata a Jason Portner por sua muito competente assistência de pesquisa e comentários editoriais e a dois generosos revisores anônimos.

Ph.D. em Relações Internacionais pela Université de Genève, na Suíça, professora de Segurança Internacional e Negociação do Departamento de Ciência Política da Northeastern University, EUA. Foi pesquisadora do Programa de Segurança Internacional, Belfer Center, Harvard University, EUA, entre 2007 e 2010. E-mail: D.Lapon@neu.edu.
} 
mentos fora do escopo do direito internacional e, portanto, aumentando o acesso a armas. A prática de transferir armamentos para atores não estatais sem critérios relativos aos usuários finais é um aspecto perene do comércio global de armamentos e, de modo geral, tem consequências deletérias. O resultado pode ser visto em conflitos prolongados, inclusive aqueles do Afeganistão, da República Democrática do Congo, do Sudão, do Chifre da África e, mais recentemente, na Síria e na Líbia. O presente artigo analisa uma emergente norma internacional putativa voltada à contenção da transferência de armas para grupos armados não estatais e inclui: comentários introdutórios e um quadro teórico; uma discussão acerca de como a transferência de armamentos para atores não estatais foi uma prática comum na Guerra Fria; um exame das origens da ideia de que esse tipo de transferência é inapropriado, seguido de sua contestação no nível multilateral; a observação de sua aceitação em certas comunidades, mas não globalmente; casos específicos de transferências de armas para atores não estatais e os efeitos disso sobre o surgimento da norma; e uma análise da contribuição deste artigo e como ele se relaciona com o direito internacional e as relações internacionais à guisa de conclusão.

\section{Introdução}

O presente artigo terá por foco o fracasso do surgimento, em nível internacional, da norma putativa proibindo a transferência de armas para atores não estatais, ${ }^{1}$ assim como a aplicabilidade limitada desta norma em nível regional. Construtivistas críticos examinam a adaptação e contestação de normas para além das fronteiras estatais, no âmbito multilateral das ideias e das práticas. Sua agenda volta-se, em última instância, ao aprimoramento da governança global. Esses teóricos visam analisar normas para além de seu contexto relativamente estável de institucionalização por meio do foco em normas em movimento, ou seu "significado-em-uso", o que caracteriza normas como continuamente contestadas, desafiadas e em competição com realidades políticas e legais emergentes (WIENER; PUETTER, 2009).

Ademais, a literatura sobre normas (especialmente nas correntes construtivistas tradicionais) tende a olhar para aquelas normas internacio- 
nais que funcionaram. Este artigo, por sua vez, volta-se a uma tentativa contestada de construção de uma norma internacional visando limitar uma prática internacional de longa data - a transferência de armamentos para atores não estatais - e suas implicações para a segurança internacional, o direito internacional e a elaboração de políticas multilaterais. O presente artigo difere, todavia, de uma abordagem construtivista comum ao examinar uma norma que, a despeito de ser difundida em contextos regionais, falhou em obter validade legal enquanto realidade normativa internacional.

O conceito de "contestação", o papel de "práticas sociais" e a distinção entre "validade legal" (tratados), "facticidade social" (reconhecimento) e "validade cultural" (significados individuais compartilhados) merecem todos serem estudados (WIENER, 2007). No caso discutido, a "validade legal" é encontrada em nível regional tanto na Europa quanto na África. Da mesma forma, a "facticidade social", ou o reconhecimento da norma, encontrou validação cultural nesses dois contextos, particularmente no caso da União Europeia (UE). Mudanças na identidade do Estado e, desse modo, no seu comportamento podem ocorrer por meio da socialização e, portanto, do aprendizado de normas e valores difundidos no sistema político com o qual o Estado interage. Esse processo se relaciona com a cognição e envolve mudar as identidades de Estados na "ausência de coerção material ou mental patente" (WIENER, 2007) (como seria o caso na presença de um hegemon). A influência social está ligada aos processos que apoiam o "comportamento condizente com a norma por meio da distribuição de benefícios e punições sociais" (JOHNSTON, 2001). O resultado dessa pressão pelos pares é a afirmação do comprometimento respectivo de cada um dos atores para com o grupo e, intrinsicamente, para com seus requisitos de pertencimento. ${ }^{3}$

Três suposições iniciais são relevantes para ir além de um debate teórico. Primeiro, irei demonstrar o conceito de "contestação" e sua função em prejudicar o reconhecimento de uma norma internacionalmente. Normas podem originar-se de dois caminhos: por meio de um quadro legal que as especifica, como um tratado, ou por meio de sua importância e aplicação social em termos do reconhecimento por um 
grupo social particular ("facticidade social"). O presente trabalho parte da premissa de que normas - e seus significados - evoluem por meio da interação com os contextos em que existem. Portanto, normas são desafiadas e questionadas em resultado à ocorrência natural de crises políticas ou por causa dos contextos envolvendo sua aplicação, podendo ser mais agudos em determinadas situações. A contestação de norma em meio à ocorrência de crises no sistema internacional é igualmente relevante e põe em evidência a necessidade de um maior entendimento normativo. Observou-se que os processos de contestação revelam seu potencial político nesses momentos de crise (WIENER, 2007).

Em segundo lugar, este artigo explora as origens de uma nova norma internacional que desafia uma prática tradicional na interação entre Estados. O foco é sobre o surgimento dessa norma e seu subsequente processo de implementação baseado na análise empírica da contestação em contextos regionais variados. Aqui, o uso de "contextos", em oposição a "níveis", faz referência aos "contextos" nos quais a interação ocorre, reconstruindo significados e constituindo legitimidade.

Em terceiro lugar, é necessário aprofundar o conceito de "estrutura normativa", fazendo referência a seus componentes de direito, normas e instituições, assim como a sua emergência e mudança (i.e., interação em contexto, práticas sociais e contestação). A estrutura normativa é composta pelos discursos e substâncias que constituem e garantem a construção e o esquema de interpretação (framing) das normas (REUS-SMIT, 1997; 2001; WIENER, 2004; FINNEMORE; SIKKINK, 1998). A evolução ou involução normativa não pode ser explicada apenas por meio da distribuição de poder em um sistema, como argumentam os neorrealistas. Da mesma forma, não pode ser explicada pela afirmação neoinstitucionalista de que países sempre tendem a criar estruturas que reduzam a incerteza e aumentem a cooperação sob a anarquia. No caso discutido, o fato de os Estados Unidos (EUA) rejeitarem a suposta norma não explica, em si mesmo, por que uma norma internacional acerca da venda de armas para atores não governamentais não foi criada e universalmente aceita. De acordo com Reus-Smit (1997), os fundamentos normativos da sociedade interna- 
cional são definidos por complexos de metavalores constitutivos. Portanto, a emergência de normas internacionais não é determinada pela configuração estrutural dos interesses de poder no sistema internacional e pelos dilemas estratégicos colocados pela cooperação, mas sim por causas mais profundas arraigadas na sociedade internacional: $o$ princípio organizador da soberania e a identidade dos Estados, i.e., a legitimidade.

A presença de uma estrutura normativa previamente existente é uma condição facilitadora para a difusão de normas (PRICE, 1997). No nível internacional, porém, esperava-se que a norma em questão "funcionasse" em contextos que não tinham quase nenhum enquadramento jurídico previamente existente. Consequentemente, ela foi contestada logo de início e falhou em se difundir internacionalmente. $\mathrm{O}$ objetivo desta análise é entender o processo dual de contestação de uma prática e de uma norma putativa, i.e., como uma prática firmemente estabelecida - Estados transferindo armas para atores não estatais operando em outros Estados - deu origem a uma norma putativa para ajudar a contestar tal prática. Tal pergunta de pesquisa reflete um importante desafio para pensadores construtivistas em geral. Como apontou Richard Price (2008), a agenda construtivista volta-se primordialmente para

[...] "boas normas" que funcionaram. Conquanto inicialmente traçado em termos metodológicos, esse desafio é ele mesmo apenas coerente dentro de seu próprio pressuposto normativo (leia-se, o que conta como "bom"). [...] Não surpreendentemente, quanto mais esse construtivismo abordou os desafios empíricos, teóricos e metodológicos postos pelos seus críticos, mais seus críticos céticos assumiram uma postura abertamente normativa. Em resposta à pletora de trabalhos acadêmicos demonstrando a importância das normas e o papel das redes transnacionais de advocacia na política internacional para acontecimentos como a Convenção sobre Minas Terrestres, a ascensão da intervenção humanitária e 
os marcos do direito penal internacional, incluindo cortes e o Tribunal Penal Internacional, críticos têm crescentemente respondido que simplesmente não concordam que tais normas sejam "boas". Por essas razões, o teorizar normativo é incontornável na tomada de posições acerca das possibilidades de mudanças morais na política internacional e, portanto, central para a prática e o discurso intelectual em Relações Internacionais, mesmo quando, profissionalmente, não lhe foi acordado um lugar de destaque nas esferas acadêmicas estadunidenses de Relações Internacionais, que têm sido dominadas por agendas explicativas que, em sua maior parte, excluem o teorizar normativo como o terreno da "teoria política", da "teoria normativa" ou da filosofia.

Assim, uma norma putativa restringindo a venda ou a transferência de armamentos para atores não estatais em outros Estados é rodeada de dilemas éticos e morais quase insuperáveis que levaram a sua contestação e falha em difundir-se internacionalmente. ${ }^{4}$ Deveria a Autoridade Palestina ser proibida de adquirir armas? Por que se assume que os Estados devem deter o monopólio sobre a produção e o fluxo de armas? Se a violência não estatal é, no mais das vezes, violência estatal disfarçada por meio de "guerras por procuração" (proxy wars), quais seriam as implicações para o entendimento das atividades de atores não estatais $?^{5}$

É um pressuposto deste artigo, porém, que a criação de limitações para a prática de transferência secreta ou aberta de armamentos por meio de um Tratado de Controle do Comércio de Armas (Arms Trade Treaty) negociado multilateralmente (a ser finalizado pela Organização das Nações Unidas (ONU) em julho de 2012, sendo o primeiro tratado legalmente vinculativo sobre armas convencionais) representaria mudança e progresso, uma vez que possui o potencial de reduzir significativamente o efeito negativo sobre a vida de civis resultante das transferências não controladas de armas convencionais. Autores realis- 
tas podem argumentar que é sempre parte do interesse dos Estados transferir armas para quem acharem legítimo e negarem a possibilidade de controlar tal transferência. Isso nos leva a um pressuposto adicional: pode ser verdade que os Estados irão sempre privilegiar sua prerrogativa irrestrita de transferir armas; todavia, o progresso na conduta das relações internacionais será alcançado quando os Estados começarem a buscar objetivos mais elevados de consulta multilateral, respeitando os direitos humanos e os critérios legais de intervenções humanitárias e exercendo limitações reais à transferência de armas para ditaduras que são as maiores perpetuadoras de violações de direitos humanos. Sob o atual sistema, a China pode transferir armas para o Sudão sob a égide da sua "relação estratégica", mesmo sabendo que tais armas serão utilizadas em Darfur. Deveria outro país, então, assumir a questão com suas próprias mãos e transferir armas para os darfurianos? Talvez não, pois, como muitos casos demonstram, essa prática levou, historicamente, a ciclos recorrentes de violência: "Tentativas de sustentar ou aumentar a segurança regional por meio de estoques de armamentos, ilustradas por países na Ásia e no Oriente Médio, parecem pouco prováveis de serem bem-sucedidas no longo prazo" (HAGELIN et al., 2001).

\section{As Origens da Norma Putativa}

As origens da ideia de criar uma norma internacional para proibir a venda de armas para atores não estatais encontram-se na proposta de dezembro de 1998 do ex-ministro das Relações Exteriores canadense, Lloyd Axworthy, de elaborar uma convenção global proibindo a transferência internacional de armas pequenas e armamentos leves para atores não estatais. $\mathrm{O}$ objetivo da convenção proposta era prevenir ou negar a transferência transfronteiriça de armamentos militares, tais como armas automáticas, granadas e lançadores e mísseis pessoal, antitanque e antiaéreo, para qualquer pessoa ou organização fora das Forças Armadas legítimas e agências de segurança.

A norma embrionária, contudo, foi imediatamente rejeitada. A proposta não incluía grupos não estatais armando-se para enfrentar governos repressivos, principalmente porque grupos de advocacia de direitos 
humanos e pesquisadores questionaram sua base no direito humanitário internacional. Em resposta a tal preocupação, Axworthy reafirmou a necessidade de estabelecer e seguir padrões que, em primeiro lugar, limitem a transferência de armas para governos que provavelmente violarão os direitos de seus próprios cidadãos. Inicialmente, os governos inglês, norueguês e alemão expressaram graus variados de aprovação da proposta canadense (LUMPE, 1999). Os alemães, então, propuseram a Ação Conjunta da União Europeia, discutida mais adiante neste capítulo.

\section{Contestação do Surgimento da Norma no Nível Internacional}

Em 2001, na Conferência das Nações Unidas sobre o Comércio Ilícito de Armas Pequenas e Armamentos Leves em todos os seus Aspectos, os Estados reuniram-se para decidir medidas e possíveis novas normas para limitar o comércio ilícito de armas. A despeito de a ênfase no comércio ilícito apenas abordar uma parte da equação global dos armamentos, as negociações foram focadas exclusivamente nesse aspecto com o intuito de manter o escopo do acordo em um mínimo denominador comum possível. Se bem-sucedido, o Tratado de Controle do Comércio de Armas estabelecerá regras para o comércio lícito de armamentos.

O Tratado de Controle do Comércio de Armas irá ajudar a determinar quando certas transferências são legítimas ou responsáveis,

[...] e quando os motivos dos fornecedores - sejam de natureza econômica, de política externa ou humanitária - são tão fortes que eles estão dispostos a correr o risco de estoques de armas agravarem o conflito. Apesar da abordagem mais inclusiva poder não ser politicamente ou praticamente realizável no nível da ONU, ela pode ser buscada para o desenvolvimento de políticas em nível nacional ou entre grupos menores de países no estabelecimento de novas normas e regulações (HAGELIN et al., 2001). 
A conferência de 2001 chegou a um acordo com relação ao Programa de Ação das Nações Unidas para Prevenir, Combater e Erradicar o Tráfico Ilícito de Armas Pequenas e Armamentos Leves em todos os seus Aspectos. O Programa de Ação tornou-se a peça central da ação multilateral contra o tráfico ilícito de armas pequenas desde 2001. Havia, à época, um amplo suporte da conferência de 2001 para a inclusão de uma cláusula proibindo a transferência de armas para atores não estatais (SMALL ARMS SURVEY DATABASE, [s.d.]). A inclusão no documento final, todavia, foi bloqueada, principalmente devido à oposição dos EUA e à aquiescência de outros Estados.

Essa contestação da norma putativa pode ser entendida ao voltar-se para seu caráter dual. Os EUA contestaram, primordialmente, a restrição multilateral da prática irrestrita de transferir armamentos, prática historicamente realizada pela maior parte dos Estados. Ademais, contestou a norma putativa internacional, a despeito de esta ser aceita, em princípio, pela maior parte dos países. A contestação baseava-se na crença de que a norma criaria artificialmente uma dicotomia entre Estados "bons" e atores não estatais "maus" (PEARTREE, 2002) e impediria, portanto, a assistência a grupos não estatais oprimidos, defendendo-se contra um governo genocida (BOLTON, 2001).

A declaração final por Camilo Reyes, presidente da Conferência da ONU de 2001, afirmou que a conferência realizara um passo significativo em abordar um dos mais urgentes problemas da paz e da segurança internacional: o comércio ilícito de armas pequenas e armamentos leves (GARCIA, 2006). Todavia, expressou sua decepção com a incapacidade da Conferência em chegar a um acordo acerca de uma norma proibindo a venda de armas para grupos não estatais com base nas preocupações de um único Estado. Ressaltou que Estados da região mais afetada pela proliferação de armas pequenas, a África, haviam relutantemente concordado com a retirada do texto proposto sobre o comércio lícito de armas pequenas e armamentos leves. Fizeram-no visando alcançar um compromisso que permitisse à comunidade global começar a mitigar uma ameaça comum. Reyes propôs, ainda, que a cláusula para atores não estatais fosse incluída ao menos no preâmbulo do documento; entretanto a delegação estadunidense opôs-se a 
essa ideia e muitas outras delegações, que também haviam contestado a norma, esconderam-se atrás dos EUA e os deixaram levar a culpa.

Dado que os EUA bloquearam a inclusão da cláusula que bania a transferência de armas para atores não estatais, é irônico que, na sequência dos ataques terroristas no World Trade Center e no Pentágono em setembro de 2001, eles declarassem que o fornecimento desregulado de armas pequenas e armamentos leves para terroristas, crime organizado e insurgentes violentos estava no centro do problema das armas pequenas (PEARTREE, 2002). Essa posição foi reforçada pela Resolução 1373 do Conselho de Segurança da ONU, emitida após os ataques de 11 de setembro, que requeria que todos os Estados membros se detivessem em prover qualquer forma de suporte, ativo ou passivo, para entidades ou pessoas envolvidas em atos terroristas, combatessem o recrutamento por grupos terroristas e eliminassem a oferta de armas para terroristas. Todavia, a despeito da Resolução 1373, os Estados Unidos reafirmaram sua forte oposição a uma norma que proibisse a venda de armas para atores não estatais.

A norma putativa proibindo a transferência de armas para atores não estatais, entretanto, adquiriu validade legal em dois contextos regionais: Europa e África.

\section{O Contexto Europeu}

A adoção da norma putativa no contexto europeu adquiriu facticidade social por meio da validação cultural de três fatores. O primeiro foi a consolidação da indústria europeia de defesa ao longo da década de 1990, que resultou em um forte incentivo econômico para a harmonização de políticas. Era do interesse da indústria que os países coordenassem melhor suas políticas de exportação de armas de modo a facilitar as transações das empresas. O segundo fator foi uma série de eventos indicando que os governos e as empresas ligadas à indústria de armas estavam evadindo as regulações e transferindo armas para países embargados. Esses eventos resultaram em reivindicações por mais transparência nos procedimentos de exportação da parte de grandes organizações não governamentais (ONGs) na Europa. Finalmente, o cenário internacional e o fim da Guerra Fria representavam a possi- 
bilidade de elaboração de políticas externas mais éticas, focadas na prevenção de conflitos e na segurança humana - conceito que já se consolidava nessa época.

O processo de facticidade social e validação cultural que culminou na validação legal da norma putativa foi extenso, ocorrendo ao longo de toda a década de 1990. O Conselho da UE de 1991 estabeleceu o Grupo de Trabalho sobre a Exportação de Armas Convencionais, com a tarefa de promover a eventual harmonização das políticas de exportação de armamentos. O primeiro critério, baseado na legislação de direitos humanos, apareceu nesse momento (BROMLEY, 2008).

O Código de Conduta para a Exportação de Armas da União Europeia foi formalmente adotado em junho de 1998 após anos de intenso lobby por ONGs do continente, tornando a UE o primeiro grupo de Estados a aceitar um código regional de conduta (UNIÃO EUROPEIA, 1998a). O Código de Conduta, politicamente vinculativo, requer que todos os membros da União Europeia usem "altos padrões comuns" quando tomando decisões no âmbito da exportação de armas e aprimorem a transparência entre si nessa temática. Com seus oito critérios, o código estabelece os padrões de conduta guiando as transferências estatais de armamentos com base nos princípios dos direitos humanos. No final de 2008, o Código de Conduta evoluiu para um instrumento legalmente vinculativo: a Posição Comum (UNIÃO EUROPEIA, 2008). Essa evolução é o resultado de um extraordinário trabalho de negociação por parte de ONGs e de fatores contingentes da política interna da UE. Mesmo esses dois instrumentos representando passos significativos para garantir que as transferências de armas ocorram dentro de critérios existentes de direito humanitário internacional e direitos humanos, eles não proíbem explicitamente a transferência de armas para atores não estatais. A decisão acerca das exportações de armamentos permanece sob o comando de cada Estado individualmente. Foi a Ação Conjunta de 1999 (reforçada em 2002) que estabeleceu tal proibição ao obrigar os Estados a fornecerem armas pequenas apenas para governos, seguindo os critérios, internacionais e regionais, apropriados para a exportação de armas, conforme delimitados particularmente no Código de Conduta da União Europeia 
(e na Posição Comum). Sob a Ação Conjunta da UE, apenas Estados são considerados usuários finais legítimos. $\mathrm{O}$ artigo $3(\mathrm{~b})$ convoca os Estados membros a

[...] um comprometimento da parte dos países exportadores a fornecer armas pequenas apenas para governos (seja diretamente ou por meio de entidades devidamente licenciadas e autorizadas a obter armas em seu nome) de acordo com os critérios regionais e internacionais de restrição à exportação de armas, conforme determinado especialmente no Código de Conduta da EU, incluindo certificados de uso final oficialmente autorizados ou, quando apropriado, outras informações relevantes sobre o uso final (UNIÃO EUROPEIA, 1998b).

\section{O Contexto Africano}

A União Africana (UA) oferece um espaço para os Estados membros desenvolverem uma posição comum no âmbito de questões ligadas a armamentos e reconhecerem a "facticidade social" do discurso e da prática de negociar políticas relativas a armas na ONU. Os africanos estavam envolvidos desde o princípio do desenvolvimento do pensamento multilateral sobre o debate a respeito das armas. As experiências de Mali na metade dos anos 1990s e seu papel de sensibilização acerca da proliferação de armas em toda a África e seus efeitos nefastos forneceram a validação cultural para que os africanos desenvolvessem a Declaração de Bamako sobre um Posicionamento Comum Africano com relação à Proliferação, Circulação e Tráfico Ilícitos de Armas Pequenas e Armamentos Leves de 2000 (Declaração de Bamako) (ORGANIZAÇÃO DE UNIDADE AFRICANA, 2000). O então presidente do Mali, Alpha Oumar Konare, tornou-se presidente da UA e teve papel decisivo em liderar os esforços no que diz respeito às políticas de armamentos no contexto africano. A Declaração de Bamako foi adotada na primeira Conferência Ministerial da Organização da União Africana sobre a Proliferação, Circulação e Tráfico Ilícito de Armas Pequenas e Armamentos Leves na África, ocorrida entre 30 de 
novembro e $1^{\circ}$ de dezembro de 2000, em Bamako. Ela expressou a posição comum africana acerca da proliferação e circulação ilícita e o tráfico de armas pequenas e armamentos leves. Isso imprimiu facticidade social em um processo de uma década de atividades no qual os africanos, os mais atingidos pelo flagelo das armas, tiveram voz. Cada sub-região africana (os países da África Oriental, a Comunidade para o Desenvolvimento da África Austral e a Comunidade Econômica dos Estados da África Ocidental [CEDEAO]) seguiu desenvolvendo seu próprio instrumento regional para o controle do tráfico de armas, fortalecendo a validade legal e a validação cultural da Declaração de Bamako.

Após Bamako, Mali apadrinhou uma resolução na Assembleia Geral da ONU intitulada Assistência aos Estados para Coibir o Tráfico Ilícito de Armas Pequenas e Coletá-las, ${ }^{*}$ que incluía textos baseados na Declaração de Bamako. Bamako faz um apelo à comunidade internacional como um todo e, particularmente, aos países fornecedores de armas, para que aceitem que o comércio de armas pequenas deve ser limitado a governos e comerciantes autorizados e registrados. Essa posição foi mantida durante os momentos finais das negociações do Programa de Ação em 2001. Os países africanos, mais afetados pelo tráfico ilícito de armamentos, estavam particularmente interessados em avançar uma cláusula proibindo a transferência de armas a atores não estatais. A inclusão desta cláusula também teria servido a regimes ditatoriais da África, uma vez que muitos deles são desafiados por movimentos hostis bem armados. É importante notar, entretanto, que os mais fortes defensores africanos da cláusula de atores não estatais eram Moçambique, África do Sul e Serra Leoa, os dois primeiros sendo democracias estáveis. ${ }^{6}$

Bamako abriu o caminho e forneceu validação cultural e facticidade social para outras vias de validação legal da norma putativa na África. A Convenção da CEDEAO de 2006 sobre Armas Pequenas e Leves, suas Munições e outros Materiais Correlatos, em seu artigo 3 (2), afirma que: "os Estados membros devem proibir, sem exceção, as

\footnotetext{
* Do inglês, Assistance to States for Curbing the Illicit Traffic in Small Arms and Collecting Them. [N. do T.]
} 
transferências de armas pequenas e armamentos leves para atores não estatais que não estejam expressamente autorizados pelo membro importador". Da mesma forma, o Protocolo de Nairobi para a Prevenção, Controle e Redução de Armas Pequenas e Armamentos Leves na Região dos Grandes Lagos e no Chifre da África de 2004 exige que os Estados exportem armamentos apenas depois de verificar que os Estados importadores possuem licenças e autorizações.

\section{Casos de Contestação de Norma Adicional e Transferência de Armamentos para Atores não Estatais}

Essa parte tem dois objetivos. O primeiro é mostrar que a ausência de uma política diplomática multilateral abrangente e, em vez disso, a busca por parte das potências globais e regionais por políticas antagônicas resultam em vácuos de "espaço normativo", como ilustrado nos casos examinados a seguir. Por sua vez, isso leva potências regionais a afirmarem sua dominação e faz com que interesses estratégicos e ideológicos superem outras considerações, incluindo a manutenção da paz e da segurança. Os casos discutidos abaixo ilustram como potências regionais não validam culturalmente a norma putativa e, em vez disso, contribuem para o enfraquecimento de sua facticidade social. O segundo objetivo é demonstrar que a interferência de partes terceiras no fornecimento de armas para atores não estatais não é mais considerada aceitável na conduta das relações internacionais hoje. A situação precária da segurança humana nas regiões discutidas, especialmente no Chifre da África, constitui um poderoso argumento a favor da negociação, por parte da comunidade internacional, de um Tratado de Controle do Comércio de Armas que harmonize as transferências de armamentos de forma que estas complementem os embargos de armas estabelecidos pelo Conselho de Segurança da ONU. O escopo desta análise limita-se a fatos ocorridos entre 2006-2007 e, mais recentemente, na Síria e na Líbia em 2011. 


\section{Hezbollah-Síria-Irã}

Em julho de 2006, o Hezbollah realizou um ataque em Israel a partir do sul do Líbano, matando oito soldados, sequestrando dois e dando início a uma guerra de 34 dias na qual 1.200 libaneses e 160 israelenses foram mortos. A Resolução 1701 do Conselho de Segurança da ONU pôs fim ao conflito, prevendo uma força internacional bastante fortalecida para manter a paz no sul do Líbano ao lado do exército libanês. Também determinou o desarmamento do Hezbollah, a proibição do envio de armas para forças não governamentais no Líbano e a demarcação clara da fronteira entre o Líbano e a Síria (ORGANIZAÇÃO DAS NAÇÕES UNIDAS, 2006a).

O fracasso em implementar a Resolução 1701 teria tido consequências graves. O secretário-geral da ONU relatou, em junho de 2007, que havia evidências do rearmamento do Hezbollah e de facções palestinas extremistas, apontando para carregamentos de armamentos pesados na fronteira sírio-libanesa (ORGANIZAÇÃO DAS NAÇÕES UNIDAS, 2007). O governo libanês relatou a apreensão de um caminhão de armas pertencentes ao Hezbollah, incluindo foguetes russos, e observou quatro caminhões levando oito lançadores de mísseis através da fronteira. Não houve controles efetivos para impedir o tráfico de armas, e as forças libaneses encarregadas da segurança fronteiriça falharam em apreender as armas contrabandeadas (BUILDUP..., 2007).

Em 2006, forças israelenses encontraram evidências de sistemas antitanques de produção russa fornecidos pela Síria em posse do Hezbollah no sul do Líbano. A Rússia respondeu às acusações anunciando, em fevereiro de 2007, que suas Forças Armadas iriam inspecionar os arsenais sírios. As relações russo-israelitas deterioraram em função dessa disputa, e a entrega de mísseis antitanques russos à Síria, do mesmo tipo encontrado com o Hezbollah, complicou ainda mais o cenário (COHEN, 2007). O relatório do secretário-geral afirma que "é crença difundida no Líbano, inclusive no governo, que o fortalecimento de postos avançados [palestinos] não poderia ter acontecido sem o conhecimento tácito e o apoio do governo sírio". O relatório ainda inclui a alegação israelense 
de que "a transferência de armamentos sofisticados por Síria e Irã pela fronteira Líbano-Síria, inclusive de foguetes de longo alcance (com alcance de 400 quilômetros) [e] sistemas antitanques e antiaéreos, ocorre semanalmente" (ORGANIZAÇÃO DAS NAÇÕES UNIDAS, 2007).

\section{O Chifre da África}

As Nações Unidas relataram que o governo eritreu tem secretamente armado um grupo radical da juventude islâmica somali conhecido como Al-Shabaab. Empresas de armas de fachada são utilizadas para comprar e fretar aeronaves e falsificar documentos para esconder carregamentos de armas. Entre os armamentos chegando à Somália, há seis mísseis terra-ar SA-18 de produção russa. Um desses foi utilizado em março para derrubar um avião de carga bielorusso no aeroporto da capital somali, Mogadíscio. A Eritreia é apenas um dos quase doze países da África e do Oriente Médio fornecendo dinheiro e armas para fundamentalistas islâmicos ativos na Somália.

O relatório também reforça o argumento de que a guerra na Somália se tornou, em parte, uma guerra por procuração entre Eritreia e Etiópia. Esses dois países permanecem inimigos desde a guerra de 1998-2002 pela demarcação de suas fronteiras. O ministro da informação eritreu afirma que falar de uma guerra por procuração na Somália é um disparate. "Por que iríamos até a Somália para fazer guerra?", perguntou. "Não temos problemas com a Etiópia além da implementação da demarcação fronteiriça, que não é uma questão política. É uma questão legal que será resolvida legalmente" (TOMLINSON, 2007). O painel da ONU notou que a Etiópia, que ainda mantém dezenas de milhares de tropas armadas na Somália, também está violando o embargo de armas. Addis Ababa afirma que suas armas são legais, uma vez que suas tropas foram convidadas para a Somália pelo governo legítimo do país (TOMLINSON, 2007).

Houve um claro aumento no número de armas na região ao longo de 2006, o que levou a União das Cortes Islâmicas a tomar Mogadíscio e grande parte do sul da Somália. O Conselho de Segurança da ONU foi informado por um relatório de novembro de 2006 que Djibouti, Egito, 
Eritreia, Irã, Líbia, Síria e Arábia Saudita, assim como o Hezbollah, ofereceram apoio à União das Cortes Islâmicas por meio de pessoal, armas e suprimentos militares, incluindo alimentos, remédios e treinamento (ORGANIZAÇÃO DAS NAÇÕES UNIDAS, 2006b). Esse relatório aponta que o Djibouti disfarçou o carregamento como pertencente ao Crescente Vermelho, em flagrante violação ao direito internacional humanitário. Etiópia, Uganda e Iêmen enviaram armas e equipamentos militares para o governo interino, à época acuado em seu único posto em Baidoa. O Iêmen forneceu armas para as autoridades em Puntlândia, ao mesmo tempo em que armava o governo de transição e a União (ORGANIZAÇÃO DAS NAÇÕES UNIDAS, 2006b, p. 27-29). O relatório destaca que esses carregamentos foram em sua maior parte retirados dos arsenais da antiga União Soviética. Outra tendência preocupante é o grande fluxo de armas através da costa somali, em sua grande parte sem monitoramento, por vias aérea e marítima (ORGANIZAÇÃO DAS NAÇÕES UNIDAS, 2006b). Todos esses países transmitiram cartas à ONU, anexadas ao relatório, negando as acusações. Não obstante, este fluxo de armas agrava significativamente o conflito na Somália.

A União beneficiou-se de tais fluxos de armamentos de diversos governos para controlar a região de Mogadíscio brevemente em 2006, proibindo a pirataria na costa e estabelecendo um sistema de coleta de impostos que substituiu aquele dos senhores da guerra. Isso foi em grande parte benéfico para a comunidade empresarial, que passou a construir laços de proximidade com a União. $\mathrm{O}$ fato de governos sentirem que têm interesses em fornecer armamentos para diferentes grupos dentro da sociedade somali pode debilitar a segurança no longo prazo. Claramente problemáticos nessa situação são os elementos extremistas que fazem parte da União: “a União das Cortes Islâmicas está bem preparada, em todos os aspectos militares relevantes [...], para travar um conflito violento, generalizado e prolongado em defesa de seus ganhos na Somália" (ORGANIZAÇÃO DAS NAÇÕES UNIDAS, 2006b, p. 42).

As dinâmicas ilustradas por esses casos apontam para o grau em que Irã e Síria, assim como os aliados dos EUA, Arábia Saudita e Egito, 
estão preparados para desafiar os interesses estadunidenses na África Oriental, a despeito da Resolução 1373 do Conselho de Segurança das Nações Unidas (LYNCH, 2006). Em última instância, o fornecimento incondicional de armas como a única moeda para a resolução de conflitos tem agravado o problema do Estado falido somali. Tal situação levou, entre outras consequências, à multiplicação de piratas nos mares ao redor do Chifre da África, perto de algumas das rotas marítimas mais estratégicas do mundo.

\section{Síria e Líbia em 2011-2012}

França e Egito supostamente transferiram armas para atores não estatais durante a guerra civil na Líbia em 2011. O Egito foi o primeiro caso confirmado de envio de armas para os rebeldes líbios (relatado em 16 de março de 2011). Os carregamentos foram disfarçados e consistiam principalmente de armas pequenas, a despeito do fato de o Egito sustentar publicamente, à época, uma postura neutra em relação ao conflito (LEVINSON; ROSENBERG, 2011). A França confirmou, em 29 de junho de 2011, que havia fornecido armas para os rebeldes líbios em diversas ocasiões. Isso representa a primeira ocorrência de um país da Organização do Tratado do Atlântico Norte (OTAN) dando apoio militar direto à oposição na Líbia (JOLLY; FAHIM, 2011).

A Resolução 1973 do Conselho de Segurança, ainda que ressalte a necessidade de fazer cumprir o embargo de armas, também autoriza os Estados membros que notificaram o secretário-geral, e agindo em cooperação com ele, a tomar todas as medidas necessárias para proteger civis sob ameaça de ataque na Líbia, não obstante o parágrafo 9 da Resolução 1970, que impôs o embargo de armas. Tal formulação, especialmente o uso do termo "não obstante", " tem sido utilizada para argumentar que a Resolução 1973 permitiria o fornecimento de armamentos, na Líbia, para atores defendendo-se da violência governamental, como parte dos esforços para proteger civis (SIPRI, [s.d.]).

\footnotetext{
* No original, “notwithstanding". [N. do T.]
} 
Portanto, não fica claro se a França violou a resolução. Mesmo afirmando que não tomara parte no fornecimento de armas para os rebeles, o Reino Unido declarou: "Acreditamos que as resoluções das Nações Unidas permitem, em certas circunstâncias limitadas, que armas defensivas sejam fornecidas, mas o Reino Unido não tomou parte nisso. Outros países interpretarão a resolução de suas próprias formas" (apud SPENCER, 2011).

A despeito da transferência de armas não violar necessariamente a Resolução 1973 devido ao linguajar abrangente empregado, a França ainda assim infringiu seus comprometimentos com a Ação Conjunta.

Não parece haver relatos confirmados de grandes transferências de armas para as forças da oposição sírias. Diversos Estados expressaram, todavia, seu interesse em fornecer suporte militar aos rebeldes sírios, especialmente diante da contínua venda de armamentos da Rússia para o regime sírio, em acréscimo ao apoio iraniano. Tanto a Arábia Saudita quanto o Qatar indicaram que estão preparados para ajudar a oposição síria (HOLD..., 2012). O primeiro-ministro do Qatar indicou que é a favor do fornecimento de armas para o mesmo grupo. O ministro das Relações Exteriores saudita, Saud al-Faisal, afirmou que armar os rebeldes sírios é "uma ótima ideia". A falta de transferências para os rebeldes da Síria pode ser explicada pela preocupação com o uso final das armas, que poderiam ser inadvertidamente entregues a extremistas. A National Public Radio (NPR) relatou que um guerreiro da oposição síria afirmou que a maior parte de suas armas é obtida de dentro do próprio país. O relatório da NPR afirma que anos de corrupção fizeram com que armas leves fossem fáceis de serem obtidas e que linhas de suprimento ilícitas do Líbano são uma das maiores fontes de armamentos (KENYON, 2012). Do lado dos Estados Unidos, tanto a Casa Branca quanto o Departamento de Estado afirmaram que podem vir a considerar "medidas adicionais" em resposta à situação na Síria, sem descartar apoio militar aos rebeldes. Isso representa uma mudança com relação a posições anteriores de que armamentos não seriam a solução para a situação (KLAPPER; LEE, 2012). 


\section{Conclusão: Implicações para o Direito Internacional e as Relações Internacionais}

O presente artigo teve por foco a contestação do surgimento da norma putativa proibindo a transferência de armas para atores não estatais no direito internacional, incluindo o subsequente processo de facticidade social e validação cultural da norma baseado em uma análise da contestação internacional e da aceitação em dois contextos regionais: a Europa e a África. O foco empírico também se estendeu ao exame da contestação da norma putativa no Oriente Médio e no Chifre da África. Assim, este artigo é em grande parte destinado a contribuir para a gama limitada de literatura construtivista voltada à análise da falha da construção de normas (em oposição ao foco tradicional na construção bem-sucedida de normas).

A contestação da norma no nível internacional pode ser largamente explicada por um dos mais longos dilemas das relações internacionais: como administrar as duas normas competitivas da integridade territorial soberana e do direito de autodeterminação dos povos que são componentes integrais da identidade dos Estados. Por um lado, os Estados são obrigados pelo direito internacional a respeitar a integridade territorial soberana de outros Estados. Por outro lado, a transferência de armas para atores não estatais buscando autodeterminação ou empoderamento político, como visto no Oriente Médio com a Primavera Árabe, é uma prática de longa data na conduta das relações internacionais. As implicações políticas e práticas de contestar o surgimento desta norma no cenário internacional são substanciais para a conduta dos assuntos internacionais no século XXI.

As implicações para o direito internacional são as seguintes. Em primeiro lugar, a falta de um regime de transferência de armas abrangente e legalmente vinculativo significa que os Estados têm amplo espaço para exportar armas de acordo com seus próprios interesses (como visto no caso da Líbia principalmente, uma vez que a França transferiu armas para atores não estatais em violação a suas obrigações em relação às regras da UE). No entanto, há um conjunto de regras que pode restringir as práticas estatais de exportação de armas. As origens des- 
sas regras são encontradas em códigos não legalmente vinculativos em vigor no direito internacional e que versam especificamente sobre armas pequenas:

Normas muitas vezes encontram a sua primeira expressão em uma declaração não vinculativa que, com o passar do tempo e o uso pelos Estados, desenvolve-se em uma regra de direito consuetudinário e, em última instância, é codificada em um tratado. [...] embora atualmente existam poucas proibições explícitas sobre as transferências de armas pequenas, há um número significativo de proibições consuetudinárias e um corpo crescente de soft law na forma de códigos de conduta limitando cada vez mais as transferências (GUILLARD, 2000).

Apesar de o politicamente vinculativo Programa de Ação de 2001 não incluir uma cláusula específica no que diz respeito às transferências de armas para atores não estatais, ele contém uma cláusula que responsabiliza os Estados pela avaliação dos pedidos de autorização de exportação segundo as "normas rígidas" e os procedimentos nacionais que dizem respeito às armas pequenas e aos armamentos leves e são "consistentes com as responsabilidades dos Estados existentes sob o direito internacional, levando em consideração especialmente o risco de desvio desses armamentos para o comércio ilegal" (ORGANIZAÇÃO DAS NAÇÕES UNIDAS, 2001, c. II, par. 11). A maior parte dos Estados, porém, não possui "normas rígidas" sobre a exportação de armas ou a capacidade de fazer valer a lei nos casos em que ela existe. Acima de tudo, muito dos Estados-chaves nessa temática não possuem a capacidade ou a legislação necessária para avaliar esse risco, especialmente quando a maioria das armas são inicialmente legais e, somente depois, desviadas para canais ilegais.

Em segundo lugar, não há nenhum acordo abrangente e legalmente vinculativo acerca do comércio internacional de armas ou comércio internacional de armas pequenas. Como mencionado acima, o Programa de Ação, negociado em 2001, é o primeiro instrumento de es- 
copo amplo regulando armas pequenas, embora de natureza apenas politicamente vinculativa. O desafio de lidar com a transferência de armas pequenas e armamentos leves para atores não estatais é agravado pelo fato de que não há regulações de qualquer tipo com relação aos armamentos convencionais maiores (tanques, aeronaves etc.) que são igualmente utilizados em conflitos. A comunidade internacional está apenas começando a negociação de um Tratado de Controle do Comércio de Armas abrangente que incluirá provisões sobre armas convencionais em geral, inclusive armas pequenas.

Em terceiro lugar, o surgimento de uma norma internacional para proibir a transferência de armas para atores não estatais parece pouco provável dentro do escopo do Tratado de Controle do Comércio de Armas, uma vez que o Tratado dificilmente incluirá uma cláusula com linguagem referente a uma norma putativa. Todavia, parece estar surgindo o reconhecimento da necessidade de estabelecer restrições e controles sobre a facilidade de acesso a armas baseados no direito internacional humanitário, e de limitar a prática há muito estabelecida de transferências não reguladas de armas com efeitos danosos sobre os civis. As negociações buscam: basear o texto do tratado nos direitos humanos internacionais e no direito humanitário internacional; estabelecer padrões universais para guiar o comércio de armas; estabelecer um quadro normativo preciso e harmonizado para o comportamento dos Estados no comércio de armas; e negociar padrões comuns mínimos para a transferência internacional de armas e seu mecanismo de operacionalização. Se bem-sucedido, o Tratado tem a oportunidade de aprimorar a governança no âmbito da paz e da segurança.

Há uma série de implicações para as relações internacionais em função da rejeição da norma prevenindo a transferência de armas para atores não estatais. Em primeiro lugar, na última década, tem havido uma conspícua falta de uma política diplomática sistemática e abrangente no âmbito de duas das regiões mais problemáticas do mundo: o Oriente Médio e o Chifre da África. Isso tem resultado em um vácuo de liderança e poder nessas regiões e, portanto, mais contestação da norma putativa, especialmente com os recentes eventos ao redor da 
"Primavera Árabe". Nesse vácuo, potências sub-regionais (ou aspirantes), como a Etiópia e a Eritreia, no Chifre da África, e a Síria, o Irã, o Qatar e a Arábia Saudita, no Oriente Médio, priorizaram seus interesses estratégicos e ideológicos, o que substituiu qualquer consideração no âmbito da manutenção da paz e da segurança. Três crises significativas da última década revelaram os benefícios potenciais de estabilização da norma putativa: os ataques de 11 de setembro de 2001 nos Estados Unidos; a guerra entre Israel e o Hezbollah no inverno de 2006; e a ascensão da União das Cortes Islâmicas na Somália e a subsequente invasão da Somália pela Etiópia e seus desdobramentos.

Em segundo lugar, buscou-se entender o processo dual de contestação de uma prática e de uma norma putativa, i.e., de que modo uma prática estabelecida - a transferência de armas para atores não estatais por parte dos Estados - levou ao surgimento de uma norma putativa que ajudaria a restringir tal prática. Uma norma restringindo a venda estatal ou a transferência de armamentos para atores não estatais em outros Estados é repleta de dilemas morais e éticos potencialmente insuperáveis que levarão, em última instância, à contestação e ao fracasso de sua difusão internacional. Todavia, no interesse da governança global, os Estados devem estabelecer critérios para as transferências permitidas de armas para atores não estatais, tal como uma norma proibindo a transferência de armas para grupos que são conhecidos por cometerem graves violações de direitos humanos. Atores não estatais têm um papel significativo nos conflitos contemporâneos e têm um impacto na vida de milhões de pessoas. Portanto, esses grupos deveriam ser responsabilizáveis diante de entendimentos normativos através de um Tratado de Controle do Comércio de Armas baseado no direito internacional humanitário, uma vez que as formas pelas quais usam armas indevidamente constituem desafio significativo à segurança humana e são danosas à paz, à segurança e à estabilidade.

Finalmente, apesar de que os Estados sempre privilegiarão sua prerrogativa irrestrita de transferir armas, há um crescente consenso de que o progresso na conduta das relações internacionais demanda que Estados respeitem os direitos humanos e o direito humanitário e exerçam 
restrição em suas práticas de transferências de armas para ditaduras, que são os piores perpetradores de violações dos direitos humanos.

\section{Notas}

10 termo "atores não estatais" refere-se a grupos armados que usam a força para atingir seus objetivos e não estão sob controle estatal, de acordo com Petrasek e Mann (2001). Trabalhos mais recentes estreitam essa definição para "grupos armados" apenas; ver Lombard (2006). Grupos armados são equipados com armas pequenas que têm a capacidade de desafiar o monopólio estatal do uso legítimo da força, de acordo com Florquin e Berman (2005).

2 Esta e as demais citações de originais estrangeiros foram livremente traduzidas para este artigo.

3 Sou grata a um extraordinário revisor anônimo.

4 Para essa discussão, ver Garcia (2009).

5 Sou grata a um revisor anônimo sobre este ponto.

6 Ver Small Arms Survey Database ([s. d.]).

\section{Referências Bïbliográficas}

BOLTON, John. Statement to the Plenary Session of the UN Conference on the Illicit Trade in Small Arms and Light Weapons in All Its Aspects. 9 jun. 2001. Disponível em: <http://www.grip.org/bdg/g1894.html>. Acesso em: 6 jun. 2012.

BROMLEY, Mark. 10 years down the track - The EU Code of Conduct on Arms Exports. European Security Review, n. 39, jul. 2008.

BUILDUP in Lebanon; heavy weapons flow freely across the border from Syria, the U.N. Security Council is told. Washington Post, 5 jul. 2007. 
COHEN, Ariel. How to confront Russia's anti-American foreign policy. Executive Summary Backgrounder No. 2048, The Heritage Foundation, 27 jun. 2007. Disponível

em: $<$ http://www.policyarchive.org/handle/10207/bitstreams/12840.pdf $>$. Acesso em: 6 jun. 2012.

FINNEMORE, Martha; SIKKINK, Kathryn. International norm dynamics and political change. International Organization, v. 52, n. 4, 1998.

FLORQUIN, Nicolas; BERMAN, Eric. Armed and aimless: armed groups, guns, and human security in the ECOWAS region. Genebra: Small Arms Survey, 2005 .

GARCIA, Denise. Small arms and security: new emerging international norms. Nova Iorque: Routledge, 2006.

Arms transfers beyond the State-to-State realm. International Studies Perspectives, v. 10, n. 2, 2009.

GUILLARD, Emanuela-Chiara. What's legal? What's illegal? In: LUMPE, L. (Org.). The global black market in small arms. Londres: Zed Books, 2000.

HAGELIN, Bjorn; WEZEMAN, Pieter; WEZEMEN, Siemon; CHIPPERFIELD, Nicolas. Transfers of major conventional weapons. In: STOCKHOLM INTERNATIONAL PEACE RESEARCH INSTITUTE. SIPRI Yearbook 2001: Armaments, Disarmament and International Security. Oxford: Oxford University Press, 2001.

HOLD your horses. The Economist, 28 jan. 2012. Disponível em: <http://www. economist.com/node/21543542>. Acesso em: 9 Mar. 2012.

JOHNSTON, Alistair. Treating international institutions as social environments. International Studies Quarterly, v. 45, n. 4, 2001.

JOLLY, David; FAHIM, Kareem. France says it gave arms to the rebels in Libya. The New York Times, 19 jun. 2011. Disponível em: <http://www.nytimes.com /2011/06/30/world/europe/30france.html>. Acesso em: 2 fev. 2012.

KENYON, Peter. Syria's rebels ask: why aren't the weapons coming? National Public Radio, 6 mar. 2012. Disponível em: <http://www.wbur.org/npr/14805 3325/syrias-rebels-ask-why-arent-the-weapons-coming>. Acesso em: 9 mar. 2012. 
KLAPPER, Bradley; LEE, Matthew. US softens stance on arms for Syrian rebels. The Associated Press, 21 fev. 2012. Disponível em: <http://www.newsday.com/ news/nation/us-softens-stance-on-arms-for-syria-rebels-1.3546268>. Acesso em: 9 mar. 2012.

LEVINSON, Charles; ROSENBERG, Matthew. Egypt said to arm Libya rebels. The Wall Stree Journal, 17 mar. 2011. Disponível em: <http://online.wsj.com/ article/SB10001424052748704360404576206992835270906.html>. Acesso em: 17 mar. 2011.

LOMBARD, Louisa. Constant threat: armed groups in West Africa. In: Small Arms Survey 2006: unfinished business. Small arms survey. Oxford: Oxford University Press, 2006.

LUMPE, Lora. Curbing the proliferation of small arms and light weapons. Security Dialogue, v. 30, n. 2, 1999.

LYNCH, Colum. U.N. report cites outside military aid to Somalia's Islamic Forces. Washington Post, 15 nov. 2006.

ORGANIZAÇÃO DAS NAÇÕES UNIDAS. Programme of Action to Prevent, Combat and Eradicate the Illicit Trade in Small Arms and Light Weapons in All Its Aspects. (A/CONF.192/15). 2001. Disponível em: <http://www.poaiss.org/ poa/poahtml.aspx>. Acesso em: 6 jun. 2012.

. Conselho de Segurança. Resolução 1701. 11 ago. 2006a.

. S/2006/913. Relatório do Grupo de Monitoramento sobre Somália. Nov. $2006 \mathrm{~b}$.

Relatório do Secretário-Geral para o Conselho de Implementação da Resolução 1701 (S/2007/147), 2007.

ORGANIZAÇÃO DE UNIDADE AFRICANA. Bamako Declaration on an African Common Position on the Illicit Proliferation, Circulation and Trafficking of Small Arms and Light Weapons, $1^{\circ}$ dez. 2000. Disponível em: <http://www. peaceau.org/uploads/bamako-declaration.pdf $>$. Acesso em: 6 jun. 2012.

PEARTREE, Edward. US Views: ban on transfers of small arms and light weapons to non-state groups. Tóquio, 24 jan. 2002. Disponível em: $<$ http://2001-2009.state.gov/t/pm/rls/rm/8766.htm>. Acesso em: 6 jun. 2012. 
PETRASEK, David; MANN, Katharine. Ends and means: human rights approaches to armed groups. Genebra: International Council on Human Rights Policy, 2001.

PRICE, Richard. The chemical weapons taboo. Ithaca: Cornell University Press, 1997.

Moral limit and possibility in world politics. International Organization, v. 62 , n. 2,2008

REUS-SMIT, Cristopher. The constitutional structure of international society and the nature of fundamental institutions. International Organization 555, v. 51, n. 4, 1997.

Human rights and the social construction of sovereignty. Review of International Studies, v. 27, n. 4, 2001.

SMALL ARMS SURVEY DATABASE. Government Documents and Statements, Country Statements and Compilations of UN 2001, Final Compilation Section II. [s.d.] Disponível em: <http://www.smallarmssurvey.org/Database. html>. Acesso em: 6 jun. 2012.

SPENCER, Richard. France supplying weapons to Libyan rebels. The Telegraph, 29 jun. 2011. Disponível em: <http://www.telegraph.co.uk/news/worldnews /africaandindianocean/libya/8606541/France-supplying-weapons-to-Libyan-rebels. html>. Acesso em: 9 mar. 2012.

STOCKHOLM INTERNATIONAL PEACE RESEARCH INSTITUTE. Arms Embargo on Libya. [s.d.]. Disponível em: $<$ http://www.sipri.org/databases/embargoes /un_arms_embargoes/libya_2/Libya_Embargo_2011>. Acesso em: 9 mar. 2012.

TOMLINSON, Chris. UN: Somalia awash in illegal arms, much of it from Eritrea. Associated Press Worldstream, 27 jul. 2007.

UNIÃO EUROPEIA. Parlamento Europeu. Resolução sobre um Código de Conduta Europeu para a Exportação de Armas, 0104/98. 15 jan. 1998a.

Ação Comum relativa ao contributo da União Europeia para o combate à acumulação e proliferação desestabilizadoras de armas pequenas e armamentos leves. 1999/34/CFSP. 17 dez. 1998b.

Posição Comum que define regras comuns aplicáveis ao controle das exportações de tecnologia e equipamento militares. 2008/944/CFSP. Jornal Oficial da União Europeia, L355/99, 8 dez. 2008. 
WIENER, Antje. Contested compliance: interventions on the normative structure of world politics. European Journal of International Relations, v. 10, n. 2, 2004.

Contested meanings of norms: the challenge of democratic governance beyond the State. Comparative European Politics, Special Issue, v. 5, n. 1, abr. 2007.

; PUETTER, Uwe. The quality of norms is what actors make of it: critical constructivist research on norms. Journal of International Law and International Relations, Special Issue, v. 5, n. 1, 2009.

\section{Resumo}

\section{Contestação de Normas e Ameaça à Paz e à Segurança Regional e Internacional: A Facilidade Excessiva de Acesso a Armas}

A facilidade de acesso a armas, pelos governos e atores não governamentais afins, exacerba os conflitos, destrói os acordos de paz frágeis e facilita a perpetração de violações dos direitos humanos e crimes hediondos contra a humanidade. Agravando isso, o comércio de armas está fora do alcance do direito internacional, ou seja, não existe um tratado global internacional juridicamente vinculativo que regulamente todos os aspectos da transferência de armas. A prática de transferência de armas para atores não estatais sem critérios em relação aos usuários finais é uma característica recorrente do comércio mundial de armas e, geralmente, tem consequências deletérias. Estas são percebidas nos conflitos prolongados no Afeganistão, na República Democrática do Congo, no Sudão, no Chifre da África, no Oriente Médio e mais recentemente na Síria e na Líbia, entre muitos outros. O presente artigo analisa uma tentativa contestada na construção de normas internacionais para conter uma prática internacional de longa data - a da transferência de armas para atores não estatais - e suas implicações para a segurança internacional, direito internacional e formulação de políticas a nível multilateral. No entanto, diferente dos construtivistas, examina uma norma que, 
apesar de difundida em diferentes contextos regionais, não conseguiu encontrar validade jurídica como uma realidade normativa internacional.

Palavras-chave: Transferência de Armas - Tratado sobre Comércio de Armas Normas Internacionais - Líbia - Síria - Chifre da África

\section{Abstract}

\section{Norm Contestation and Threat to Regional and International Peace and Security: Excessive Ease of Access to Arms}

The ease of access to arms, by governments and non-government actors alike, exacerbates conflicts, destroys fragile peace agreements, and facilitates the perpetration of violations of human rights and egregious crimes against humanity. Compounding this, the arms trade is out of the purview of International Law; that is, there is no comprehensive legally binding international treaty regulating all aspects of arms transfers. The practice of transferring arms to non-state actors with no criteria regarding the end users is a recurrent feature of the global arms trade, and usually has deleterious consequences. These are perceived in the protracted conflicts in Afghanistan, the Democratic Republic of the Congo, Sudan, the Horn of Africa and the Middle East more recently in Syria and Libya, among many others. The present article looks at a contested attempt at international norm building to restrain a long-held international practice - that of transferring arms to non-state actors - and its implications for international security, international law and policymaking at the multilateral level. However, different from the constructivists, it examines a norm that, although diffusing in different regional contexts, has failed to find legal validity as an international normative reality.

Keywords: Arms Transfers - Arms Trade Treaty - International Norms - Libya - Syria - Horn of Africa 